\title{
Peeking across Grain Boundaries in a Solid- State Ionic Conductor
}

Swapna Ganapathy, ${ }^{* \dagger}$ Chuang Yu, ${ }^{\dagger}$ Ernst R. H. van Eck, ${ }^{\dagger}$ and Marnix Wagemaker ${ }^{*}{ }^{\dagger}$

${ }^{\dagger}$ Department of Radiation Science and Technology, Delft University of Technology, Mekelweg 15, Delft 2629JB, The Netherlands ${ }^{\ddagger}$ Institute for Molecules and Materials, Radboud University, Heyendaalseweg 135, Nijmegen 6525AJ, The Netherlands

Supporting Information

ABSTRACT: The development of high-performance all-solid-state batteries relies on charge transport in solid electrolytes, where transport across grain boundaries often limits their bulk conductivity. The argyrodite $\mathrm{Li}_{6} \mathrm{PS}_{5} \mathrm{X}(\mathrm{X}=\mathrm{Cl}, \mathrm{Br})$ solid electrolyte has a high conductivity; however, macroscopic diffusion in this material involves complex jump processes, which leads to an underestimation of the activation energy. Using a comprehensive frequency- and temperature-dependent analysis of the spin-lattice relaxation rates, a complete estimation of $\mathrm{Li}$ self-diffusion is demonstrated. Another experimental challenge is quantifying the impact of grain boundaries on the total bulk conductivity. $\mathrm{Li}_{6} \mathrm{PS}_{5} \mathrm{Cl}$ and $\mathrm{Li}_{6} \mathrm{PS}_{5} \mathrm{Br}$ have identical crystalline structures, but with ${ }^{6} \mathrm{Li}$ MAS NMR, their resonance peaks have different chemical shifts. Exploiting this with two-dimensional ${ }^{6} \mathrm{Li}-{ }^{6} \mathrm{Li}$ exchange NMR on a mixture of $\mathrm{Li}_{6} \mathrm{PS}_{5} \mathrm{Br}$ and $\mathrm{Li}_{6} \mathrm{PS}_{5} \mathrm{Cl}$, we observe $\mathrm{Li}$ exchange between particles of these two materials across grain boundaries, allowing direct and unambiguous
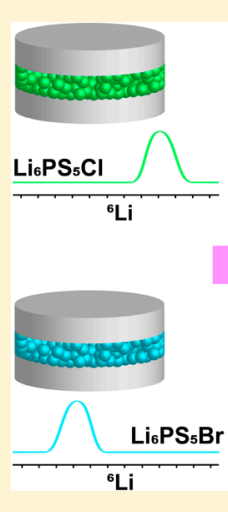

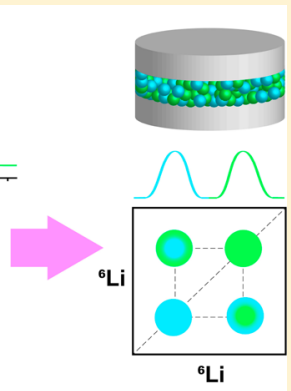

$0.27 \mathrm{eV}$ quantification of this often limiting process in solid-state electrolytes.

$\mathrm{L}$ ife today is unimaginable without our mobile devices, the functioning of which is predominantly facilitated by the use of Li-ion batteries based on their high energy density. With the increasing demands on batteries, all solidstate Li-ion batteries are conceptually very attractive, providing several advantages over current liquid electrolyte-based Li-ion batteries. ${ }^{1-3}$ The main benefit is that safety hazards associated with the flammability of conventional liquid electrolytes can be circumvented by using solid electrolytes. ${ }^{1,3,4}$ The use of solid electrolytes could potentially allow more freedom in cell design, modified packaging that could allow for an increase in energy density. In addition, several solid electrolytes have been purported to offer a larger electrochemical stability window, enabling the use of high-voltage cathode materials that often fall on the edge of the electrochemical stability of liquid electrolytes. ${ }^{4}$ The main factors that have hindered the application of solid electrolytes in Li-ion batteries are the high charge transport resistance between the solid electrolyte and the battery electrode as well as resistance across the grain boundaries of individual solid electrolyte particles, ${ }^{2,5,6}$ limiting the bulk conductivity.

Solid-state nuclear magnetic resonance (NMR) is a versatile and nondestructive technique that can be used to characterize the structure and dynamics of materials. The bulk Li-ion selfdiffusion parameters for a Li-ion solid-state conductor can often be determined from an NMR spin-lattice relaxometry (SLR) analysis. ${ }^{7,8}$ Additionally, it is possible to follow $\mathrm{Li}$ transport across the electrode-electrolyte interface, both with solid $^{2,5}$ and liquid ${ }^{9}$ electrolytes, allowing for quantification of interfacial charge transport using both one- and two-dimensional exchange NMR spectroscopy (2D-EXSY). This is based on the ability to identify the individual spectral contributions of each species due to a difference in chemical shift arising from the different chemical environments in which Li resides in the electrode and electrolyte. One aspect of Li-ion transport, however, remains difficult to unambiguously assess with solidstate NMR, which is $\mathrm{Li}$ transport across grain boundaries within a solid-state Li-ion conductor. This is because each grain has the same spectral signature, making them "identical" from an NMR perspective within the limited chemical shift windows of ${ }^{6} \mathrm{Li}$ and ${ }^{7} \mathrm{Li}$.

The argyrodite $\mathrm{Li}_{6} \mathrm{PS}_{5} \mathrm{X}(\mathrm{X}=\mathrm{Cl}, \mathrm{Br})$ solid electrolyte belongs to the family of sulfur-based solid electrolytes, which have become extremely popular recently because their conductivity approaches that of liquid electrolytes. ${ }^{2,5,10-13}$ They possess high room-temperature conductivity on the order of $10^{-3}-10^{-2} \mathrm{~S} / \mathrm{cm}^{5,13-15}$ and the precursors needed to synthesize the solid electrolyte are cheap, and synthesis is straightforward. ${ }^{14}$ Chlorine- and bromine-containing $\mathrm{Li}_{6} \mathrm{PS}_{5} \mathrm{Cl}$ and $\mathrm{Li}_{6} \mathrm{PS}_{5} \mathrm{Br}$ have identical crystalline structures and exhibit comparable bulk conductivities. ${ }^{12,14-16}$ Previous relaxation NMR experiments resulted in low activation energies for bulk diffusion, especially for the argyrodite $\mathrm{Li}_{6} \mathrm{PS}_{5} \mathrm{X}(\mathrm{X}=\mathrm{Cl}, \mathrm{Br})$ synthesized by the solid-state method, ${ }^{14,15,17}$ possibly indicat-

Received: March 20, 2019

Accepted: April 15, 2019

Published: April 15, 2019 

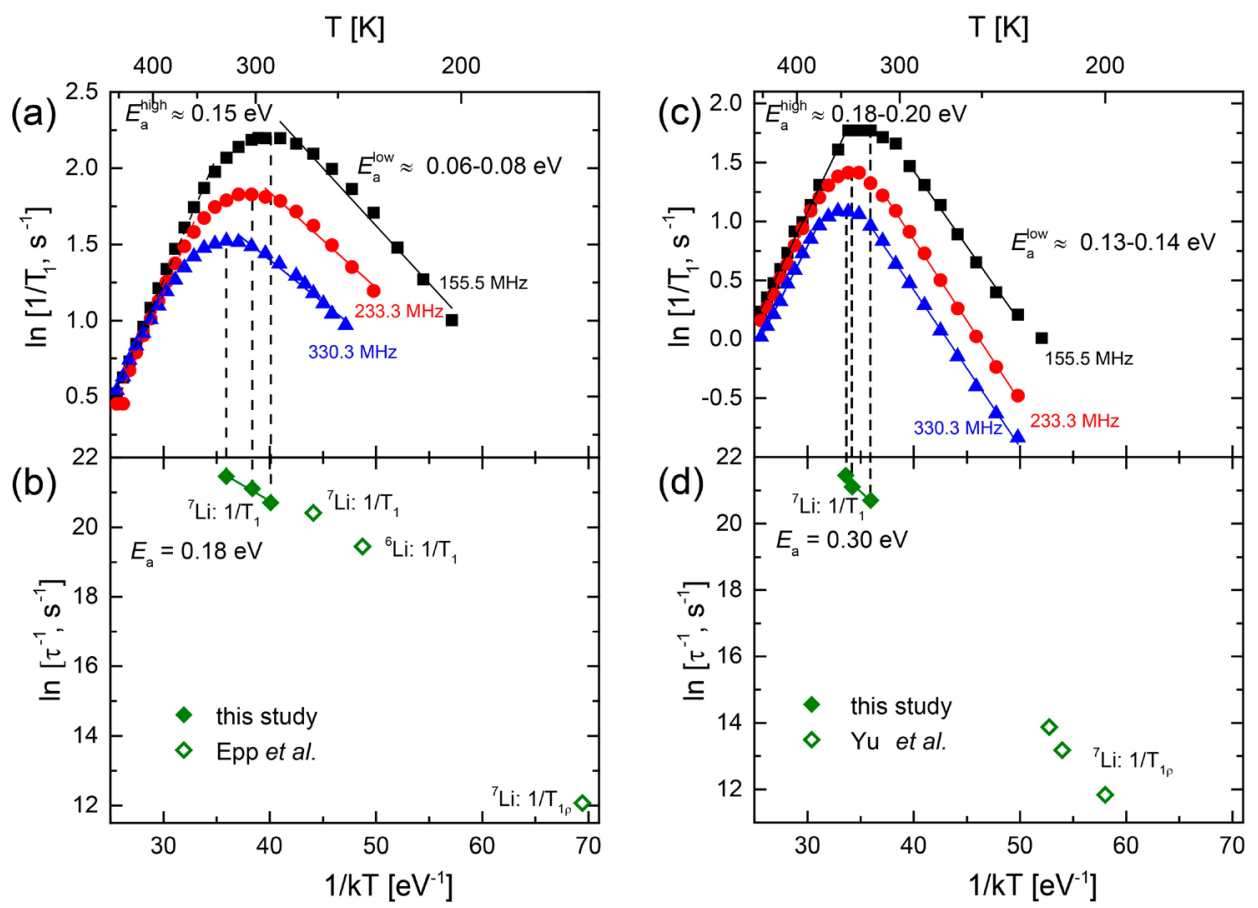

Figure 1. ${ }^{7} \mathrm{Li}$ SLR rates of $\mathrm{Li}_{6} \mathrm{PS}_{5} \mathrm{Br}(\mathrm{a})$ and $\mathrm{Li}_{6} \mathrm{PS}_{5} \mathrm{Cl}$ (c) plotted as a function of reciprocal temperature, measured at three different field strengths $(9.4,14.1$, and $20 \mathrm{~T})$. The lines on the curves represent an Arrhenius fit of the low-temperature and high-temperature flanks corresponding to short- and long-range diffusion processes, respectively. (b,d) Lithium jump rates extracted from the SLR data in (a,c) determined by using the relation $\omega_{0} \tau \approx 1$. $^{7}$ The solid line represents a global Arrhenius fit yielding an activation energy $E_{\mathrm{a}}$. Jump rates reported by Epp and co-workers ${ }^{17}$ from ${ }^{6,7} \mathrm{Li}$ SLR $\left(1 / T_{1(\rho)}\right)$ measurements of $\mathrm{Li}_{6} \mathrm{PS}_{5} \mathrm{Br}$ and Yu and co-workers ${ }^{5}$ for $\mathrm{Li}_{6} \mathrm{PS}_{5} \mathrm{Cl}_{\text {have been }}$ included for comparison.

ing that the wide spectral distribution in hopping frequencies may hinder accurate determination of the activation energy. Here, using a complete frequency- and temperature-dependent SLR rate analysis ${ }^{18}$ in the laboratory frame of reference, we are able to completely quantify $\mathrm{Li}$ diffusion within grains of the $\mathrm{Li}_{6} \mathrm{PS}_{5} \mathrm{Br}$ and $\mathrm{Li}_{6} \mathrm{PS}_{5} \mathrm{Cl}$ solid electrolyte, resulting in more consistent activation energies and providing a simple NMR strategy to accurately determine bulk conductivities. Facilitated by the difference in ${ }^{6} \mathrm{Li} \mathrm{NMR}$ chemical shifts of $\mathrm{Li}_{6} \mathrm{PS}_{5} \mathrm{Br}$ and $\mathrm{Li}_{6} \mathrm{PS}_{5} \mathrm{Cl}$ due to the difference in $\mathrm{Li}$ shielding of the halogen dopants and by mixing $\mathrm{Li}_{6} \mathrm{PS}_{5} \mathrm{Br}$ and $\mathrm{Li}_{6} \mathrm{PS}_{5} \mathrm{Cl}$, this essentially "labels" the $\mathrm{Li}$ species, which allows the quantification of $\mathrm{Li}$ exchange between electrolyte grains using ${ }^{6} \mathrm{Li}-{ }^{6} \mathrm{Li} 2 \mathrm{D}$-EXSY NMR. This provides insight into the Li diffusion in these solid electrolytes, obtained by directly quantifying the Li-ion diffusion over the grain boundaries. Thereby, direct and unambiguous quantification of this often limiting charge transport process in solid electrolytes is achieved, providing insight into the impact of solid electrolyte grain boundaries.

Solid-state NMR has been previously used ${ }^{5,15,17}$ to quantify bulk diffusion for both $\mathrm{Li}_{6} \mathrm{PS}_{5} \mathrm{Cl}$ and $\mathrm{Li}_{6} \mathrm{PS}_{5} \mathrm{Br}$. This is done via SLR measurements in both the laboratory $\left(T_{1}\right)$ as well as rotating $\left(T_{1 \rho}\right)$ frame of reference. As long as changes in $T_{1(\rho)}$ are induced by Li-ion mobility (and not structural changes), temperature-dependent $T_{1(\rho)}$ measurements can be used to quantify the jump rate $\tau^{-1}$ and associated activation energy $E_{a}$ where the jump rate follows the Arrhenius condition giving $\tau^{-1}$ $=\tau_{0}^{-1} \exp \left(-E_{\mathrm{a}} / k_{\mathrm{B}} T\right)$. When the SLR rate $\left(1 / T_{1}\right)$ attains a maximum value as a function of temperature, then the jump frequency $\tau^{-1}$ is on the order of the Larmor frequency $\omega_{0}$ (or spin-lock frequency $\omega_{1}$ for $\left.1 / T_{1 \rho}\right)$, where $\tau$ is the time between hops. $^{7,18-20}$ Because the Larmor frequency $\omega_{0}$ is typically on the order of $\mathrm{MHz}$ and the spin-lock frequencies $\omega_{1}$ are on the order of $\mathrm{kHz}$, diffusion can be probed on several length scales. At the maximum SLR rate $1 / T_{1}\left(1 / T_{1 \rho}\right)$, the condition $\omega_{0} \tau_{\mathrm{c}} \approx$ $1\left(\omega_{1} \tau_{\mathrm{c}} \approx 0.5\right)$ holds, a consequence of efficient energy transfer between the Li-ions and their environment. The SLR rates in the laboratory $\left(1 / T_{1}\right)$ and rotating $\left(1 / T_{1 \rho}\right)$ frames of reference are directly related to the spectral density function, ${ }^{21}$ and assuming a three-dimensional diffusion process, the SLR rates in the high-temperature regime, $\tau \omega_{0} \ll 1$, are proportional to the Li-ion residence time $\tau$, while the SLR rates in the lowtemperature regime, $\tau \omega_{0} \gg 1$, are proportional to $\tau^{-1} \omega_{0(1)}{ }^{-\beta}$ $\ll 1$ (with $1<\beta \leq 2$ ). Because it is assumed that the residence time $\tau$ shows typical Arrhenius behavior, the slopes of the highand low-temperature regions of the SLR rate curves can be used to determine the activation energies for the Li-ion diffusional process, where the low- and high-temperature slopes correspond to short- and long-range motional processes, respectively.

The argyrodite structure is built around a $\mathrm{PS}_{4}$ backbone with $\mathrm{P}$ atoms occupying the $4 \mathrm{~b}$ sites and $\mathrm{S}$ atoms belonging to the $\mathrm{PS}_{4}$ unit occupying the $16 \mathrm{e}$ sites. ${ }^{10}$ The remaining $\mathrm{S}$ and halogen atoms occupy the $4 \mathrm{a}$ and $4 \mathrm{c}$ sites, while approximately $50 \%$ of the surrounding $48 \mathrm{~h}$ sites are occupied by $\mathrm{Li}$ atoms. ${ }^{22}$ Within the crystal, as determined from first-principle molecular dynamics (MD) simulations, three main kinds of $\mathrm{Li}$ jumps dominate. $^{23}$ The first is between neighboring Li sites (pairs) separated by $1.9 \AA$, of which only one $\mathrm{Li}$ site per pair is occupied, and jumps between these neighboring sites are called back-and-forth jumps. Twelve $48 \mathrm{~h}$ sites, i.e., six pairs, form a cage arranged around each $4 \mathrm{c}$ site. The jumps within this cage between $\mathrm{Li}$ atoms belonging to different pairs have been defined as intracage jumps with a jump distance of $2.25 \AA$. The 
final kind of jump occurs between $\mathrm{Li}$ atoms belonging to different cages and is called the intercage jump, the jump length of which is variable. Intuitively, on the basis of the short jump distances and confirmed via MD simulations, the backand-forth jumps are energetically the cheapest and most abundant, possessing a high jump rate with an activation barrier of $\sim 0.10 \mathrm{eV}$ for both the $\mathrm{Cl}$ - and $\mathrm{Br}$-doped variants determined at $300 \mathrm{~K}^{23}$ The intracage jumps appear only slightly more expensive with an activation barrier of $\sim 0.11 \mathrm{eV}$ but with a lower jump frequency. ${ }^{23}$ The intercage jumps require the largest activation barrier of $\sim 0.18 \mathrm{eV}$ but with a very low jump rate, likely the limiting factor to macroscopic diffusion. ${ }^{23}$ For $\mathrm{Li}_{6} \mathrm{PS}_{5} \mathrm{Br}$, an activation energy $\left(E_{\mathrm{a}}\right)$ of $0.2 \mathrm{eV}$ was reported by Epp and co-workers ${ }^{17}$ for the hightemperature region, which is representative of "bulk" or longrange Li-ion mobility in the solid electrolyte. Our previously published results ${ }^{15}$ on a material with the same composition, albeit prepared using a different method, resulted in an even lower activation energy of $0.15 \mathrm{eV}$ for bulk Li-ion diffusion. All of these values are on the lower side for bulk diffusion, especially in comparison with those deduced for bulk diffusion from AC impedance spectroscopy, of 0.38 and $0.58 \mathrm{eV}$ as reported by Dieseroth and co-workers ${ }^{24}$ and $\sim 0.45$ and $\sim 0.3$ $\mathrm{eV}$ reported by $\mathrm{Kraft}$ and co-workers ${ }^{12}$ for the $\mathrm{Li}_{6} \mathrm{PS}_{5} \mathrm{Cl}$ and $\mathrm{Li}_{6} \mathrm{PS}_{5} \mathrm{Br}$ solid electrolytes, respectively. The discrepancy could originate from the contribution of grain boundaries to the $\mathrm{AC}$ impedance spectroscopy-derived activation energies where bulk and grain boundary contributions are more difficult to decouple. This is also seen in a study performed by Dawson and co-workers, ${ }^{25}$ where it is demonstrated computationally that unless contributions from grain boundaries are taken into consideration the overall activation energy is underestimated.

In addition, the aforementioned high complexity of the diffusion process for the argyrodite, involving a combination of three kinds of jumps to achieve macroscopic diffusion, most likely results in broadening of the hopping-induced spectral density, leading to an underestimation of the activation energy to bulk diffusion as derived from SLR NMR. Additionally, the activation energy obtained from the slope of the hightemperature flank possibly reflects only the back-and-forth jumps and intracage jumps, which have high jump rates and the lowest-energy barriers.

To quantify the bulk diffusion in both the Cl- and $\mathrm{Br}$ - doped variants of the argyrodites synthesized by the method described in $\mathrm{Yu}$ et al., ${ }^{14}$ SLR NMR measurements as a function of temperature and resonance frequency were measured at three different ${ }^{7} \mathrm{Li}$ Larmor frequencies $\left(\omega_{0} / 2 \pi\right)$, i.e., 330.3, 233.3, and 155.5 MHz. From the SLR rate curves shown in Figure $1 \mathrm{a}, \mathrm{c}$ for the $\mathrm{Li}_{6} \mathrm{PS}_{5} \mathrm{Br}$ and $\mathrm{Li}_{6} \mathrm{PSCl}$ argyrodites, respectively, maxima were obtained for each of the relaxation curves within the measured temperature range and are given in Tables 1 and 2. The low- and high-temperature flanks of the SLR rate curves could be fit with an Arrhenius relation, and the

Table 1. Values Obtained for the SLR NMR Curves Shown in Figure $1 \mathrm{a}$ for the $\mathrm{Li}_{6} \mathrm{PS}_{5} \mathrm{Br}$ Argyrodite

$\begin{array}{cccccc}\begin{array}{c}\omega_{0} / 2 \pi \\ (\mathrm{MHz})\end{array} & E_{\mathrm{a}}^{\text {low }}(\mathrm{eV}) & E_{\mathrm{a}}^{\text {high }}(\mathrm{eV}) & \beta & \begin{array}{c}T_{\max } \\ (\mathrm{K})\end{array} & \tau_{0}^{-1}\left(\mathrm{~s}^{-1}\right) \\ 155.5 & 0.076 \pm 0.004 & 0.162 \pm 0.003 & 1.47 & 290 & 6.4 \times 10^{11} \\ 233.3 & 0.063 \pm 0.004 & 0.164 \pm 0.006 & 1.38 & 303 & 7.8 \times 10^{11} \\ 330.3 & 0.056 \pm 0.003 & 0.139 \pm 0.004 & 1.40 & 323 & 3.1 \times 10^{11}\end{array}$

Table 2. Values Obtained for the SLR NMR Curves Shown in Figure 1a for the $\mathrm{Li}_{6} \mathrm{PS}_{5} \mathrm{Cl}$ Argyrodite

\begin{tabular}{cccccc}
$\begin{array}{c}\omega_{0} / 2 \pi \\
(\mathrm{MHz})\end{array}$ & $E_{\mathrm{a}}^{\text {low }}(\mathrm{eV})$ & $E_{\mathrm{a}}^{\text {high }}(\mathrm{eV})$ & $\beta$ & $\begin{array}{c}T_{\max } \\
(\mathrm{K})\end{array}$ & $\tau_{0}^{-1}\left(\mathrm{~s}^{-1}\right)$ \\
155.5 & $0.128 \pm 0.003$ & $0.187 \pm 0.003$ & 1.68 & 322 & $8.3 \times 10^{11}$ \\
233.3 & $0.137 \pm 0.002$ & $0.199 \pm 0.002$ & 1.69 & 339 & $1.3 \times 10^{12}$ \\
330.3 & $0.133 \pm 0.002$ & $0.177 \pm 0.003$ & 1.75 & 345 & $8.0 \times 10^{11}$ \\
\hline
\end{tabular}

activation energies and pre-exponential factors thus obtained are in Tables 1 and 2 .

As reported previously, ${ }^{5,14,15}$ we observe that the SLR rate curves of the $\mathrm{Li}_{6} \mathrm{PS}_{5} \mathrm{Br}$ argyrodite exhibit maxima at lower temperatures than those of the $\mathrm{Li}_{6} \mathrm{PS}_{5} \mathrm{Cl}$ argyrodite across all three frequencies measured, which is an indication of faster local $\mathrm{Li}$ mobility at ambient temperatures. The activation energy of the low-temperature flank typically represents shortrange jumps; therefore, on the basis of the values obtained from the fits, i.e., $0.05-0.08 \mathrm{eV}$ for $\mathrm{Li}_{6} \mathrm{PS}_{5} \mathrm{Br}$ and $0.12-0.14 \mathrm{eV}$ for the $\mathrm{Li}_{6} \mathrm{PS}_{5} \mathrm{Cl}$ argyrodite, it is likely that this represents backand-forth diffusion of Li-ions in the $48 \mathrm{~h}$ pairs. The activation energies obtained from the high-temperature flank are 0.13$0.17 \mathrm{eV}$ for the $\mathrm{Li}_{6} \mathrm{PS}_{5} \mathrm{Br}$ and $0.17-0.20 \mathrm{eV}$ for the $\mathrm{Li}_{6} \mathrm{PS}_{5} \mathrm{Cl}$ argyrodite, which should represent longer-range diffusional processes, mediated by the intracage and intercage Li jumps. These values are in good agreement with the activation energies for the intercage jumps predicted by DFT MD simulations, ${ }^{23}$ where the jump behavior of $\mathrm{Li}$ in the argyrodite with various halogen dopants was studied. It is, however, much smaller than values obtained from impedance spectroscopy, which despite contributions from grain boundaries, indicates that even the high-temperature flank is representative of backand-forth and at best intracage diffusion. This indicates that a single SLR rate curve may, despite having a well-defined maximum, be an unreliable measure for systems where bulk diffusion comprises different kinds of complex jump processes.

Even though SLR rates measured in the rotating frame offer information about diffusion occurring on longer time and diffusion length scales, i.e., jump rates on the order of $10^{4}-10^{5}$ $\mathrm{s}^{-1}$, the $T_{1 \rho}$ values that we obtained from spin-lock measurements performed previously ${ }^{5,15}$ required a stretched exponential to fit, providing two and sometime three $T_{1 \rho}$ components. On the other hand, each relaxation rate $\left(1 / T_{1}\right)$ obtained from the saturation recovery experiment could be fit relatively easily with a single exponent, yielding a single $T_{1}$ value. To evaluate the bulk diffusion within both the $\mathrm{Li}_{6} \mathrm{PS}_{5} \mathrm{Br}$ and $\mathrm{Li}_{6} \mathrm{PS}_{5} \mathrm{Cl}$ argyrodite variants, a global Arrhenius fit was performed using the jump rates $\tau^{-1}$ obtained from the maxima of the SLR rate curves measured at the various ${ }^{7} \mathrm{Li}$ Larmor frequencies depicted in Figure $1 \mathrm{~b}, \mathrm{~d}$ for the $\mathrm{Li}_{6} \mathrm{PS}_{5} \mathrm{Br}$ and $\mathrm{Li}_{6} \mathrm{PS} \mathrm{S}_{5} \mathrm{Cl}$ argyrodites, yielding $\tau^{-1}=1 \times 10^{12} \mathrm{~s}^{-1} \exp (-0.18(3) \mathrm{eV} /$ $\left.k_{\mathrm{B}} T\right)$ and $\tau^{-1}=5 \times 10^{13} \mathrm{~s}^{-1} \exp \left(-0.29(7) \mathrm{eV} / k_{\mathrm{B}} T\right)$, respectively. The values for the Arrhenius pre-exponential factor obtained from the global fit fall within the range of typical phonon frequencies, unlike the values for $\tau_{0}^{-1}$ obtained from fitting the individual SLR rate data seen from Tables 1 and 2, where the values are underestimated. The activation energy values obtained from the global fit of 0.18(3) and $0.29(7) \mathrm{eV}$ for the $\mathrm{Li}_{6} \mathrm{PS}_{5} \mathrm{Br}$ and $\mathrm{Li}_{6} \mathrm{PS}_{5} \mathrm{Cl}$ argyrodite, respectively, are both higher than values obtained from the high-temperature flank of the individual relaxation rate curves (Tables 1 and 2) and more representative of actual bulk diffusion within the argyrodite crystals. The differences 
between the activation energies for the $\mathrm{Br}$ - and $\mathrm{Cl}$-doped variants have been ascribed to the difference in lattice softness ${ }^{12}$ between the $\mathrm{Li}_{6} \mathrm{PS}_{5} \mathrm{Br}$ and $\mathrm{Li}_{6} \mathrm{PS}_{5} \mathrm{Cl}$ argyrodites, where the softer lattice of the former results in a lower activation energy and also a lower pre-exponential factor, which are not necessarily concomitant with a higher ionic conductivity.

2D-EXSY NMR allows one to track the mobility of Li-ions from one site to the other, based on the difference in chemical shift arising from differences in local chemical environments. $\mathrm{Li}$ motion can be tracked as a function of both temperature and exchange time, also called the mixing time " $T_{\text {mix }}$ ". The final factor that effects the 2D-EXSY measurement is the SLR time or $T_{1}$ of the Li species that are under study because in order to be measured, quantifiable exchange must occur at a $T_{\text {mix }}$, which is shorter than $T_{1}$. Both ${ }^{7} \mathrm{Li}$ and ${ }^{6} \mathrm{Li}$ are NMR "active" nuclei, with the higher natural abundance of the former often making it the nucleus of choice to be studied. On the other hand, despite its lower natural abundance and low gyromagnetic ratio, the weaker dipolar and quadrupolar interactions associated with ${ }^{6} \mathrm{Li}$ often result in spectra having better resolution than that achieved for ${ }^{7} \mathrm{Li}$. In addition, $T_{1}$ 's tend to be longer for ${ }^{6} \mathrm{Li}$ than those for ${ }^{7} \mathrm{Li}$.

When studying exchange between individual Li-containing species, i.e., different materials vs Li-ion sites within a material or crystallite, often the interfacial contact area is relevant because there have to be sufficient points of access to track measurable Li-ion mobility. To achieve this condition for the mixture of $\mathrm{Br}$ - and $\mathrm{Cl}$-doped argyrodite materials, the electrolyte materials were each individually ball-milled to reduce particle size and thereby increase surface area, before they were mixed together gently in a mortar with a pestle. The mixture was then subsequently pressed into a pellet with $\sim 5$ ton $/ \mathrm{cm}^{2}$ pressure. The pellet was then crushed into a fine powder, which was then used for NMR measurements. A onedimensional (1D) single-pulse MAS spectrum of the mixture is given in Figure 2. It is seen that the individual contributions from the $\mathrm{Li}_{6} \mathrm{PS}_{5} \mathrm{Br}$ and $\mathrm{Li}_{6} \mathrm{PS}_{5} \mathrm{Cl}$ argyrodite powders are preserved (Figure 2), where the $\mathrm{Li}_{6} \mathrm{PS}_{5} \mathrm{Br}$ fraction gives a peak at $\sim 2 \mathrm{ppm}$ and the $\mathrm{Li}_{6} \mathrm{PS}_{5} \mathrm{Cl}$ fraction gives a peak at $\sim 1 \mathrm{ppm}$.

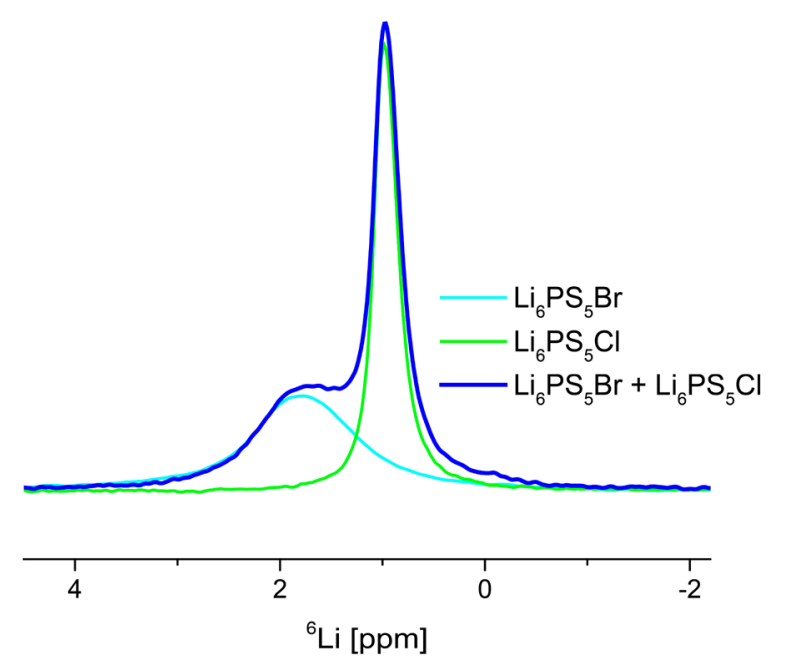

Figure 2. One-dimensional (1D) MAS ${ }^{6} \mathrm{Li}$ NMR spectra of the nanosized $\mathrm{Li}_{6} \mathrm{PS}_{5} \mathrm{Br}$ and $\mathrm{Li}_{6} \mathrm{PS}_{5} \mathrm{Cl}$ and a mixture of nanosized $\mathrm{Li}_{6} \mathrm{PS}_{5} \mathrm{Br}$ and $\mathrm{Li}_{6} \mathrm{PS}_{5} \mathrm{Cl}$ measured at a spinning speed of $10 \mathrm{kHz}$ and a temperature of $25^{\circ} \mathrm{C}$.
There is some broadening observed for the Br-doped argyrodite, which could be a result of the ball-milling, which gives rise to a large amorphous fraction, resulting in line broadening. Another strategy was tried that entailed ballmilling of individual powders of $\mathrm{Li}_{6} \mathrm{PS}_{5} \mathrm{Cl}$ and $\mathrm{Li}_{6} \mathrm{PS}_{5} \mathrm{Br}$ together to create a mixture with sufficient interfacial contact. This strategy however proved unsuccessful because even at low rpm ball-milling speeds (110 rpm) a mixed $\mathrm{Li}_{6} \mathrm{PS}_{5} \mathrm{Br}_{x} \mathrm{Cl}_{y}$ species with a single $\mathrm{Li}$ environment was seen via a single NMR peak in the ${ }^{6} \mathrm{Li}$ spectrum.

$2 \mathrm{D}{ }^{6} \mathrm{Li}-{ }^{6} \mathrm{Li}$ exchange spectra of the mixture were measured at various temperatures and mixing times, of which the spectra measured at $25{ }^{\circ} \mathrm{C}$ are depicted in Figure 3. As seen for $T_{\text {mix }}=$ $10 \mathrm{~ms}$, no appreciable cross-peak intensity is observed, which is a measure of lithium that has moved from the $\mathrm{Li}_{6} \mathrm{P}_{5} \mathrm{Br}$ phase to the $\mathrm{Li}_{6} \mathrm{PS}_{5} \mathrm{Cl}$ phase in the mixture and vice versa. Upon increasing the mixing time, $T_{\text {mix }}$ toward $100 \mathrm{~ms}-1 \mathrm{~s}$, a clear increase in cross-peak intensity is observed. The evolution of normalized cross-peak intensity as a function of $T_{\text {mix }}$ measured at $25,50,75$, and $100{ }^{\circ} \mathrm{C}$ within a $T_{\text {mix }}$ range of $1 \mathrm{~ms}-2 \mathrm{~s}$ (up to $1 \mathrm{~s}$ for $100{ }^{\circ} \mathrm{C}$ ) is depicted in Figure 4a. Spectra measured for $T_{\text {mix }}$ values of $2 \mathrm{~s}$ (Figure 4a), showed a sharp drop in crosspeak intensity likely due to a decline in diagonal intensity due to $T_{1}$. Exchange between the $\mathrm{Li}_{6} \mathrm{PS}_{5} \mathrm{Br}$ and $\mathrm{Li}_{6} \mathrm{PS}_{5} \mathrm{Cl}$ phases was quantified by fitting the evolution of the cross-peak intensity as a function of $T_{\text {mix }}$ to a diffusion model derived from Fick's law, which has been described by us in in detail elsewhere. ${ }^{5,9}$ From the fit, the diffusion coefficient $(D)$ as a function of temperature can be obtained, which in this case pertains to Li-ion transport across the electrolyte-electrolyte interface. Here we make the assumption that diffusion occurs from the center of a $\mathrm{Li}_{6} \mathrm{PS}_{5} \mathrm{Br}$ particle to the center of a $\mathrm{Li}_{6} \mathrm{PS}_{5} \mathrm{Cl}$ particle. From the peak width of the XRD patterns of the nanosized $\mathrm{Br}$ - and $\mathrm{Cl}$-doped argyrodites, we get an average crystallite size of $\sim 20 \mathrm{~nm}$ for each phase, which we assume to be the maximum diffusion distance. The diffusion coefficients as a function of temperature obtained from the fit are given in Figure $4 \mathrm{~b}$. The values obtained for the diffusion coefficient are directly related to the diffusion distance, which in this case may be an overestimation. The data for electrolyte-electrolyte diffusion across grain boundaries can be fit to an Arrhenius law, yielding an activation energy of $0.27(4) \mathrm{eV}$. This is comparable to the activation energy obtained for bulk diffusion from global fit of the NMR relaxometry measurements for the $\mathrm{Li}_{6} \mathrm{PS}_{5} \mathrm{Cl}$ argyrodite, which indicates that (a) it is possible to determine the activation energy for diffusion across grain boundaries and (b) diffusion across grain boundaries is not rate-limiting for the case of the argyrodite solid electrolytes.

In conclusion, using a comprehensive frequency- and temperature-dependent analysis of the SLR rates in the laboratory frame of reference, we are able to perform a complete estimation of $\mathrm{Li}$ self-diffusion within the argyrodite $\mathrm{Li}_{6} \mathrm{PS}_{5} \mathrm{X}(\mathrm{X}=\mathrm{Br}, \mathrm{Cl})$ solid electrolyte. It is found that a multiple frequency SLR analysis is essential, ${ }^{18}$ especially for systems with complex local diffusion processes. Exploiting the difference in chemical shift of the $\mathrm{Cl}$ - and $\mathrm{Br}$-containing variants of the argyrodite, we use $2 \mathrm{D}{ }^{6} \mathrm{Li}-{ }^{6} \mathrm{Li}$ solid-state NMR to determine the barrier for $\mathrm{Li}$-ion transport across grain boundaries, which are found not to be rate-limiting for the case of the argyrodite solid electrolyte. This is not surprising because thiophosphates are known to be highly ductile materials, which can be considered responsible for the low grain boundary resistance. ${ }^{26}$ Unravelling the contribution of 

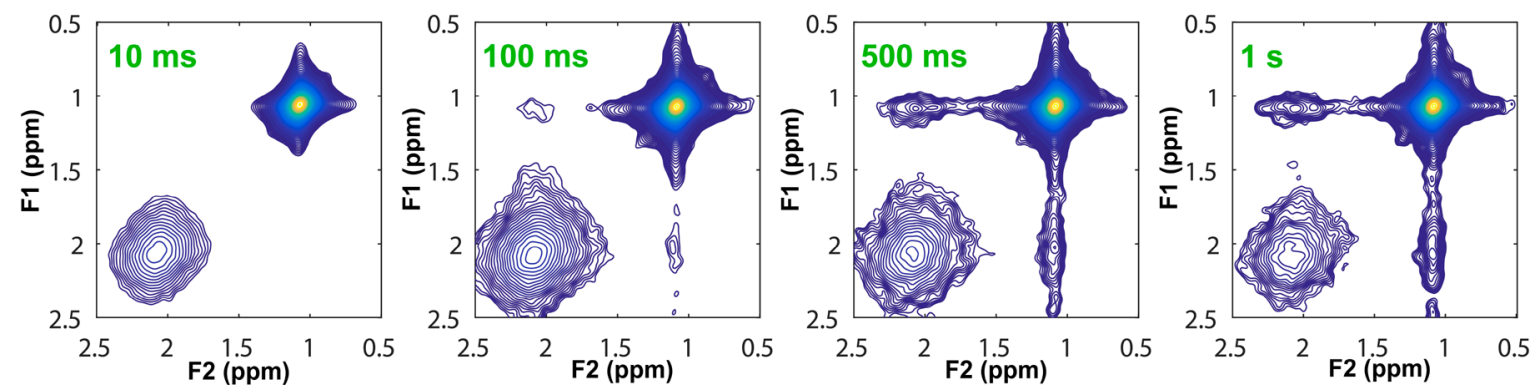

Figure 3. Two-dimensional ${ }^{6} \mathrm{Li}-{ }^{6} \mathrm{Li}$ exchange spectra of the mixture of $\mathrm{Li}_{6} \mathrm{PS}_{5} \mathrm{Br}$ and $\mathrm{Li}_{6} \mathrm{PS}_{5} \mathrm{Cl}$ nanopowders measured at $25{ }^{\circ} \mathrm{C}$ with mixing times of $10 \mathrm{~ms}, 100 \mathrm{~ms}, 500 \mathrm{~ms}$, and $1 \mathrm{~s}$ at a spinning speed of $10 \mathrm{kHz}$. The spectrum consists of 16 scans for each of the 32 slices, each slice incremented by $8 \mathrm{~ms}$ with a recycle delay of $5 \mathrm{~s}$. Cross-peaks are seen between each of the two peaks on the diagonal.

(a)

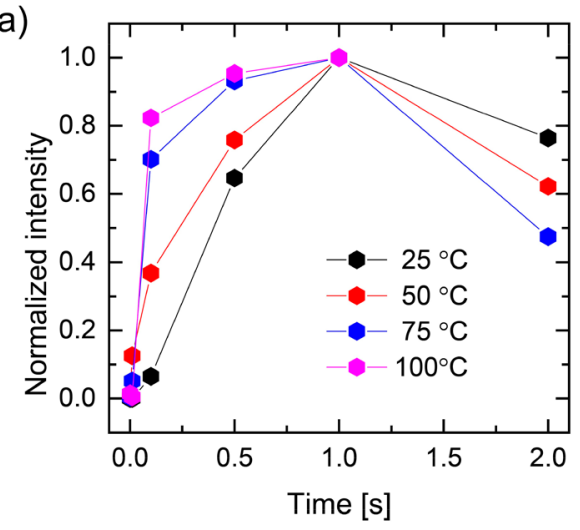

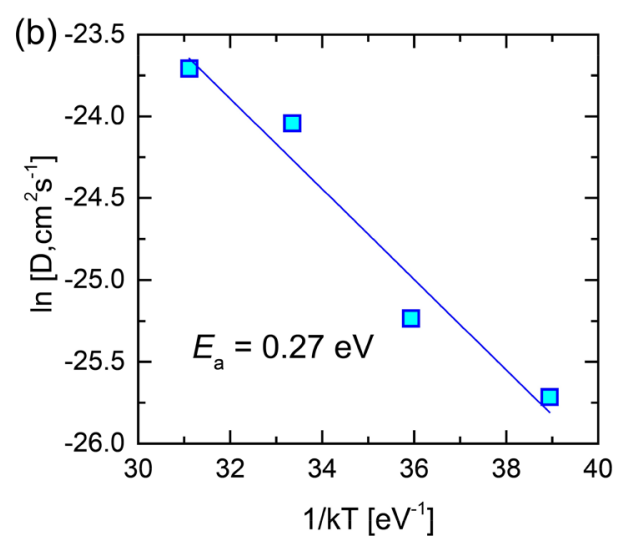

Figure 4. (a) Evolution of cross-peak intensity as a function of $T_{\text {mix }}$ obtained from the 2D-EXSY measurements done at the temperatures indicated in the graph. The line passing through the symbols is a guide to the eye. (b) Dependence of the diffusion coefficient obtained from fitting the data in (a) to a diffusion model described in detail elsewhere. ${ }^{9}$ These can be fit with the Arrhenius law, yielding an activation energy $\left(E_{\mathrm{a}}\right)$ of $0.27 \mathrm{eV}$.

grain boundaries is tedious but essential if the potential bulk conductivity of solid electrolytes is to be completely exploited. The presented NMR "labeling" method makes it possible to attain formerly difficult to access information about ionic transport across grain boundaries.

\section{EXPERIMENTAL METHODS}

The argyrodites $\mathrm{Li}_{6} \mathrm{PS}_{5} \mathrm{Cl}$ and $\mathrm{Li}_{6} \mathrm{PS}_{5} \mathrm{Br}$ used have been synthesized as described in ref 14. A detailed description of the materials and synthesis is given in the Supporting Information. ${ }^{7} \mathrm{Li}$ SLR NMR measurements were performed using a saturation recovery experiment at magnetic field strengths of 9.4, 14.1, and $20 \mathrm{~T}$ for both argyrodite solid electrolytes. 2D-EXSY MAS NMR measurements of a mixture of $\mathrm{Li}_{6} \mathrm{PS}_{5} \mathrm{Cl}$ and $\mathrm{Li}_{6} \mathrm{PS}_{5} \mathrm{Br}$ was performed at a magnetic field strength of $14.1 \mathrm{~T}$, with a $T_{\text {mix }}$ range of $1 \mathrm{~ms}-2 \mathrm{~s}$ and in a temperature range of $25-100{ }^{\circ} \mathrm{C}$. A detailed description is given in the Supporting Information.

\section{ASSOCIATED CONTENT}

\section{S Supporting Information}

The Supporting Information is available free of charge on the ACS Publications website at DOI: 10.1021/acsenergylett.9b00610.

Detailed experimental section (PDF)

\section{AUTHOR INFORMATION}

\section{Corresponding Authors}

*E-mail: s.ganapathy@tudelft.nl.

*E-mail: m.wagemaker@tudelft.nl.

\section{ORCID}

Marnix Wagemaker: 0000-0003-3851-1044

Notes

The authors declare no competing financial interest.

\section{ACKNOWLEDGMENTS}

The technical assistance of Frans Ooms at the TUD and Hans Janssen and Gerrit Janssen at the RUN is gratefully acknowledged. Support from the Dutch organization of scientific research (NWO) is gratefully acknowledged for the solid-state NMR facility for advanced materials science in Nijmegen and for VICI Grant Number 16122 to M.W.

\section{REFERENCES}

(1) Janek, J.; Zeier, W. G. A Solid Future for Battery Development. Nat. Energy 2016, 1, 16141.

(2) Yu, C.; Ganapathy, S.; van Eck, E. R. H.; Wang, H.; Basak, S.; Li, Z.; Wagemaker, M. Accessing the Bottleneck in All-Solid State Batteries, Lithium-Ion Transport over the Solid-Electrolyte-Electrode Interface. Nat. Commun. 2017, 8, 8.

(3) Kato, Y.; Hori, S.; Saito, T.; Suzuki, K.; Hirayama, M.; Mitsui, A.; Yonemura, M.; Iba, H.; Kanno, R. High-Power All-Solid-State Batteries Using Sulfide Superionic Conductors. Nat. Energy 2016, 1, 16030. 
(4) Knauth, P. Inorganic Solid Li Ion Conductors: An Overview. Solid State Ionics 2009, 180, 911-916.

(5) Yu, C.; Ganapathy, S.; de Klerk, N. J. J.; Roslon, I.; van Eck, E. R. H.; Kentgens, A. P. M.; Wagemaker, M. Unravelling Li-Ion Transport from Picoseconds to Seconds: Bulk Versus Interfaces in an Argyrodite Li6PS ${ }_{5} \mathrm{Cl}-\mathrm{Li}_{2} \mathrm{~S}$ All-Solid-State Li-Ion Battery. J. Am. Chem. Soc. 2016, 138, 11192-11201.

(6) Liang, J.-Y.; Zeng, X.-X.; Zhang, X.-D.; Wang, P.-F.; Ma, J.-Y.; Yin, Y.-X.; Wu, X.-W.; Guo, Y.-G.; Wan, L.-J. Mitigating Interfacial Potential Drop of Cathode-Solid Electrolyte Via Ionic Conductor Layer to Enhance Interface Dynamics for Solid Batteries. J. Am. Chem. Soc. 2018, 140, 6767-6770.

(7) Epp, V.; Wilkening, M., Li-Ion Dynamics in Solids as Seen Via Relaxation NMR. In Handbook of Solid State Batteries, 2 ed.; Dudney, N. J., West, W. C., Nanda, J., Eds.; World Scientific, 2015; pp 133190.

(8) Schmidt-Rohr, K.; Spiess, H. W. Multidimensional Solid-State NMR and Polymers. Academic Press: London, 1994.

(9) Ganapathy, S.; van Eck, E. R.; Kentgens, A. P.; Mulder, F. M.; Wagemaker, M. Equilibrium Lithium-Ion Transport between Nanocrystalline Lithium-Inserted Anatase $\mathrm{TiO}_{2}$ and the Electrolyte. Chem. Eur. J. 2011, 17, 14811-14816.

(10) Deiseroth, H.-J.; Kong, S.-T.; Eckert, H.; Vannahme, J.; Reiner, C.; Zaiß, T.; Schlosser, M. $\mathrm{Li}_{6} \mathrm{PS}_{5} \mathrm{X}$ : A Class of Crystalline Li-Rich Solids with an Unusually High $\mathrm{Li}^{+}$Mobility. Angew. Chem., Int. Ed. 2008, 47, 755-758.

(11) Boulineau, S.; Tarascon, J.-M.; Leriche, J.-B.; Viallet, V. Electrochemical Properties of All-Solid-State Lithium Secondary Batteries Using Li-Argyrodite $\mathrm{Li}_{6} \mathrm{PS}_{5} \mathrm{Cl}$ as Solid Electrolyte. Solid State Ionics 2013, 242, 45-48.

(12) Kraft, M. A.; Culver, S. P.; Calderon, M.; Böcher, F.; Krauskopf, T.; Senyshyn, A.; Dietrich, C.; Zevalkink, A.; Janek, J.; Zeier, W. G. Influence of Lattice Polarizability on the Ionic Conductivity in the Lithium Superionic Argyrodites $\mathrm{Li}_{6} \mathrm{PS}_{5} \mathrm{X}(\mathrm{X}=\mathrm{Cl}, \mathrm{Br}, \mathrm{I})$. J. Am. Chem. Soc. 2017, 139, 10909-10918.

(13) Kraft, M. A.; Ohno, S.; Zinkevich, T.; Koerver, R.; Culver, S. P.; Fuchs, T.; Senyshyn, A.; Indris, S.; Morgan, B. J.; Zeier, W. G. Inducing High Ionic Conductivity in the Lithium Superionic Argyrodites $\mathrm{Li}_{6+X} \mathrm{P}_{1-X} \mathrm{Ge}_{X} \mathrm{~S}_{5} \mathrm{I}$ for All-Solid-State Batteries. J. Am. Chem. Soc. 2018, 140, 16330-16339.

(14) Yu, C.; Ganapathy, S.; Hageman, J.; van Eijck, L.; van Eck, E. R.; Zhang, L.; Schwietert, T.; Basak, S.; Kelder, E. M.; Wagemaker, M. Facile Synthesis toward the Optimal Structure-Conductivity Characteristics of the Argyrodite $\mathrm{Li}_{6} \mathrm{PS}_{5} \mathrm{Cl}$ Solid-State Electrolyte. ACS Appl. Mater. Interfaces 2018, 10, 33296-33306.

(15) Yu, C.; Ganapathy, S.; Van Eck, E. R. H.; Van Eijck, L.; Basak, S.; Liu, Y.; Zhang, L.; Zandbergen, H. W.; Wagemaker, M. Revealing the Relation between the Structure, Li-Ion Conductivity and SolidState Battery Performance of the Argyrodite $\mathrm{Li}_{6} \mathrm{PS}_{5} \mathrm{Br}$ Solid Electrolyte. J. Mater. Chem. A 2017, 5, 21178-21188.

(16) Rao, R. P.; Adams, S. Studies of Lithium Argyrodite Solid Electrolytes for All-Solid-State Batteries. Phys. Status Solidi A 2011, 208, 1804-1807.

(17) Epp, V.; Gün, Ö.; Deiseroth, H.-J.; Wilkening, M. Highly Mobile Ions: Low-Temperature NMR Directly Probes Extremely Fast $\mathrm{Li}^{+}$Hopping in Argyrodite-Type $\mathrm{Li}_{6} \mathrm{PS}_{5} \mathrm{Br}$. J. Phys. Chem. Lett. 2013, 4, 2118-2123.

(18) Kuhn, A.; Kunze, M.; Sreeraj, P.; Wiemhöfer, H.-D.; Thangadurai, V.; Wilkening, M.; Heitjans, P. NMR Relaxometry as a Versatile Tool to Study Li Ion Dynamics in Potential Battery Materials. Solid State Nucl. Magn. Reson. 2012, 42, 2-8.

(19) Wilkening, M.; Heitjans, P. From Micro to Macro: Access to Long-Range $\mathrm{Li}^{+}$Diffusion Parameters in Solids Via Microscopic ${ }^{6,7} \mathrm{Li}$ Spin-Alignment Echo NMR Spectroscopy. ChemPhysChem 2012, 13, $53-65$.

(20) Kuhn, A.; Narayanan, S.; Spencer, L.; Goward, G.; Thangadurai, V.; Wilkening, M. Li Self-Diffusion in Garnet-Type $\mathrm{Li}_{7} \mathrm{La}_{3} \mathrm{Zr}_{2} \mathrm{O}_{12}$ as Probed Directly by Diffusion-Induced ${ }^{7} \mathrm{Li}$ Spin-
Lattice Relaxation NMR Spectroscopy. Phys. Rev. B: Condens. Matter Mater. Phys. 2011, 83, 094302.

(21) Heitjans, P.; Kärger, J. Diffusion in Condensed Matter: Methods, Materials, Models; Springer Science \& Business Media, 2006.

(22) Rayavarapu, P.; Sharma, N.; Peterson, V.; Adams, S. Variation in Structure and $\mathrm{Li}^{+}$-Ion Migration in Argyrodite-Type $\mathrm{Li}_{6} \mathrm{PS}_{5} \mathrm{X}(\mathrm{X}=$ $\mathrm{Cl}, \mathrm{Br}, \mathrm{I})$ Solid Electrolytes. J. Solid State Electrochem. 2012, 16, $1807-1813$.

(23) de Klerk, N. J. J.; Roslon, T.; Wagemaker, M. Diffusion Mechanism of Li Argyrodite Solid Electrolytes for Li-Ion Batteries and Prediction of Optimized Halogen Doping: The Effect of Li Vacancies, Halogens, and Halogen Disorder. Chem. Mater. 2016, 28, 7955-7963.

(24) Deiseroth, H.-J.; Maier, J.; Weichert, K.; Nickel, V.; Kong, S.T.; Reiner, C. $\mathrm{Li}_{7} \mathrm{PS}_{6}$ and $\mathrm{Li}_{6} \mathrm{PS}_{5} \mathrm{X}(\mathrm{X}: \mathrm{Cl}, \mathrm{Br}, \mathrm{I})$ : Possible ThreeDimensional Diffusion Pathways for Lithium Ions and Temperature Dependence of the Ionic Conductivity by Impedance Measurements. Z. Anorg. Allg. Chem. 2011, 637, 1287-1294.

(25) Dawson, J. A.; Canepa, P.; Famprikis, T.; Masquelier, C.; Islam, M. S. Atomic-Scale Influence of Grain Boundaries on Li-Ion Conduction in Solid Electrolytes for All-Solid-State Batteries. J. Am. Chem. Soc. 2018, 140, 362-368.

(26) Seino, Y.; Ota, T.; Takada, K.; Hayashi, A.; Tatsumisago, M. A Sulphide Lithium Super Ion Conductor Is Superior to Liquid Ion Conductors for Use in Rechargeable Batteries. Energy Environ. Sci. 2014, 7, 627-631. 